\title{
PERAMALAN JUMLAH TITIK PANAS PROVINSI KALIMANTAN TIMUR MENGGUNAKAN METODE RADIAL BASIS FUNCTION NEURAL NETWORK
}

\author{
Siti Aisyah $^{1}$, Sri Wahyuningsih ${ }^{2}$, Fidia Deny Tisna Amijaya ${ }^{3}$ \\ ${ }^{1}$ Laboratorium Statistika Terapan, Fakultas MIIPA, Universitas Mulawarman \\ ${ }^{2}$ Program Studi Statistika, Fakultas MIPA, Universitas Mulawarman \\ ${ }^{3}$ Program Studi Matematika, Fakultas MIPA, Universitas Mulawarman \\ e-mail: aisyah228sa@gmail.com
}

\begin{abstract}
Abstrak
Radial Basis Function Neural Network (RBFNN) merupakan neural network yang menggunakan fungsi radial basis pada hidden layernya untuk tujuan klasifikasi maupun peramalan. Neural Network yang dikembangkan menjadi fungsi radial basis dengan sistem pemrosesan informasi yang memiliki karakteristik mirip dengan jaringan saraf biologi, terdiri dari lapisan input, lapisan tersembunyi, dan lapisan output. Data yang digunakan dalam penelitian ini yaitu data jumlah titik panas di Provinsi Kalimantan Timur diperoleh dari website resmi National Aeronautics and Space Administration (NASA). Tujuan penelitian ini adalah memperoleh model RBFNN dan hasil peramalan jumlah titik panas periode Januari 2020 sampai Maret 2020. Fungsi radial basis yang digunakan adalah fungsi Gaussian yang bersifat lokal dan fungsi aktivasi linier. Pada penelitian ini menggunakan proporsi data training dan data testing 70:30; 80:20; dan 90:10. Hasil penelitian menunjukkan bahwa jaringan input menggunakan Partial Autocorrelation Function (PACF) yang signifikan terdapat pada lag 1 dan lag 2 sehingga model RBFNN yang terbentuk melibatkan $\mathrm{X}_{\mathrm{t}-1}$ dan $\mathrm{X}_{\mathrm{t}-2}$. Mean Absolute Percentage Error (MAPE) minimum diperoleh pada proporsi data 80:20 dengan 2 jaringan tersembunyi. Arsitektur RBFNN yang terbentuk adalah 2 lapisan input, 2 lapisan tersembunyi dan 1 lapisan output. Data hasil peramalan jumlah titik panas di Provinsi Kalimantan Timur menunjukkan dari periode Januari 2020 sampai Februari 2020 terjadi penurunan dan bulan Maret 2020 mengalami kenaikan.
\end{abstract}

Kata Kunci: Fungsi Gaussian, MAPE, Peramalan, RBFNN, Titik Panas.

\begin{abstract}
Radial Basis Function Neural Network (RBFNN) is a neural that uses a radial base function in hidden layers for classification and forecasting purposes. Neural Network is developed into a radial function base with an information processing system that has characteristics similar to biological neural networks, consisting of input layers, hidden layers, and output layers. The data used in this study is data on the number of hotspots in East Kalimantan Province obtained from the official website of the National Aeronautics and Space Administration (NASA). The purpose of this research is to obtain the RBFNN model and the results of forecasting the number of hotspots for the period January 2020 to March 2020. The radial basis function used is the local Gaussian function and the linear activation function. In this study using the proportion of training data and testing data 70: 30; 80:20; and 90:10. The results showed that the input network using significant Partial Autocorrelation Function (PACF) at lag 1 and lag 2, so that the RBFNN model that was formed involved $X_{t-1}$ and $X_{t-2}$. The best Mean Absolute Percentage Error (MAPE) minimum obtained the 80:20 data proportion with 2 hidden networks. The RBFNN architecture that is formed is 2 input layers, 2 hidden layers and 1 output layer. Data from forecasting the number of hotspots in East Kalimantan Province shows that from January 2020 to February 2020 there was a decline and March 2020 an increase.
\end{abstract}

Keywords: Gaussian function, MAPE, Forecasting, RBFNN, Hotspot. 


\section{PENDAHULUAN}

Titik panas hanya akan memberikan informasi sedikit apabila tidak dilakukan interpretasi dan analisis lanjutan untuk mengetahui kemunculan titik panas sebagai upaya mitigasi kebakaran lahan. Satelit yang dikenal untuk mendeteksi titik panas adalah satelit NOAA (National Oceanic and Atmospheric Administration), Terra/Aqua MODIS, maupun data satelit penginderaan jauh. Titik panas perlu diketahui pada periode berikutnya dapat menjadikan suatu pertimbangan dalam melakukan suatu tindakan dikarenakan wilayah Kalimantan Timur menurut Global Wetlands merupakan salah satu dari 10 Provinsi di Indonesia yang memiliki lahan gambut terluas pada urutan ke tujuh sebesar 0,9 juta ha yang dapat menyebabkan kebakaran lahan hutan (Tim Publikasi Kata Data 2019). Berdasarkan data SiPongi, Karhutla tahun 2019 Monitoring Sistem, Kementerian Lingkungan Hidup dan Kehutanan, luas kebakaran hutan dan lahan di Kalimantan Timur pada 2019 mencapai 6.715 hektar yang salah satunya disebabkan oleh Titik Panas di Provinsi Kalimantan Timur (Direktorat Pengendalian Kebakaran Hutan dan Lahan 2021) .

Peramalan (forecasting) merupakan teknik untuk memprakirakan suatu nilai pada masa yang akan datang dengan memperhatikan data masa lalu maupun data pada saat ini (Aswi and Sukarna 2006). Metode yang digunakan dalam peramalan antara lain exponensial smoothing, double exponensial smoothing, Regresi, ARIMA. Model RBFNN sendiri terdiri dari jaringan lapisan masukan (input), lapisan tersembunyi (hidden) dan lapisan keluaran (output). Penerapan RBFNN memiliki kemampuan untuk mengelompokkan suatu kasus analisis data dan peramalan berdasarkan struktur jaringannya. Perkembangan selanjutnya berkembang metode menggunakan skema Jaringan Saraf Tiruan (JST) atau Neural Network (NN) (Nievergelt 1969). Salah satu metode peramalan yang tergolong dalam model NN adalah model Radial Basis Function Neural Network.

RBFNN pertama kali digunakan untuk memecahkan permasalahan interpolasi multivariat. RBFNN hanya memiliki bobot pada jaringan yang terhubung dari lapisan tersembunyi ke lapisan output, terdapat fungsi aktivasi yang digunakan yaitu fungsi aktivasi Gaussian pada lapisan tersembunyi dan mengeluarkan nilai berupa persamaan nonlinier, sedangkan pada lapisan output atau akhir proses RBFNN mengeluarkan nilai berupa persamaan linier (Palit and Popović 2005).

Penelitian tentang titik panas antara lain oleh Al-mar'atush Shoolihah (Shoolihah et al. 2017) yang melakukan analisa implementasi metode improved k-means untuk mengelompokkan titik panas bumi. Salah satu kesimpulan yang diperoleh bahwa improved $k$-means yang dilakukan dengan dua tahapan yaitu memilih titik pusat awal dan melakukan pengelompokkan data dengan metode $k$-means clustering.

Penelitian yang telah dilakukan menggunakan RBFNN yaitu (Nikentari et al. 2018) yang memprediksi kecepatan angin menggunakan adaptive neuro fuzzy (ANFIS) dan RBFNN. Hasil pengujian menggunakan kedua algoritma tersebut memperlihatkan akurasi terbaik Root Mean Square Error (RMSE) diperoleh oleh RBFNN.

Berdasarkan penelitian tersebut menunjukkan bahwa analisis metode Radial Basis Function Neural Network dapat digunakan untuk data runtun waktu dan salah satu penelitian data runtun waktu yaitu titik panas. Titik panas di Provinsi Kalimantan Timur perlu dilakukan peramalan menggunakan metode Radial Basis Function Neural Network agar informasi yang diperoleh secara umum bisa tersampaikan bahwa pentingnya menjaga kelestarian hutan untuk mengindari terjadinya titik panas yang terbentuk. Berdasarkan hal tersebut penelitian akan membahas peramalan jumlah titik panas Provinsi Kalimantan Timur pada bulan Januari 2020 sampai dengan Maret 2020 menggunakan metode Radial Basis Function Neural Network. 


\section{METODE PENELITIAN}

Pada penelitian ini metode yang digunakan adalah studi literatur dengan menelusuri jurnal jurnal dan buku teks yang terkait dengan Radial Basis Function Neural Network dan titik panas Provinsi Kalimantan Timur. Langkah-langkah peramalan dengan metode RBFNN menggunakan software $R$ 3.5.3 adalah sebagai berikut:

1. Membuat grafik runtun waktu jumlah data titik panas di Provinsi Kalimantan Timur.

2. Membagi data training dan data testing

Pada proses ini data dibagi menjadi dua bagian yaitu data training dan data testing. Proporsi pembagian data bersifat subjektif tergantung peneliti. Persentase data training lebih besar dibanding dengan data testing. Data testing yang dapat digunakan $10 \%$ sampai $30 \%$ dari data terakhir.

\section{a. Pembagian data training}

Data training yang digunakan pada penelitian ini dengan komposisi 70\%,80\%, dan $90 \%$. Proses pembentukan data training yaitu dengan cara menggunakan komposisi yang telah ditentukan dari jumlah seluruh data. Sehingga data training yang terbentuk antara lain komposisi $70 \%$ diperoleh 84 data training, 80\% diperoleh 96 data training dan $90 \%$ diperoleh 108 data training. Berdasarkan data training yang diperoleh kemudian digunakan untuk menentukan pemodelan RBFNN.

\section{b. Pembagian data testing}

Pada penelitian ini data testing merupakan sisa komposisi data yang terlah digunakan pada data training. Komposisi yang digunakan antara lain 10\%,20\%, dan 30\%. Data testing yang diperoleh yaitu untuk komposisi 30\% ada 36 data, 20\% diperoleh 24 data dan $90 \%$ diperoleh 12 data. Hasil data testing digunakan untuk menentukan pemodelan RBFNN yang terbaik dengan tingkat akurasi.

\section{Menentukan model RBFNN}

Pada proses ini dilakukan perhitungan untuk mencari nilai output yang akan digunakan untuk peramalan dan data yang digunakan adalah data training. Berikut tahap menentukan model RBFNN.

a. Menentukan input jaringan

Menurut Budi Warsito dalam (Warsito 2009) peramalan time series data masa kini dipengaruhi oleh data masa lalu, sehingga hal ini data pada model RBFNN adalah data masa lalu (lag time) dan targetnya adalah data masa kini, sebagaimana terminologi autoregressive pada metode ARIMA Box-Jenkis. Penentuan input jaringan dilakukan menggunakan Partial Autocorrelation Function yang digunakan untuk mengukur keeratan antara $\mathrm{X}_{\mathrm{t}}$ dan $\mathrm{X}_{\mathrm{t}+\mathrm{k}}$, apabila pengaruh dari time lag dianggap terpisah (Makridakis et al. 1999). Menentukan input jaringan melihat lag-lag yang signifikan pada plot PACF jika melewati selang kepercayaan (Laksmi et al. 2014).

b. Menentukan banyak neuron pada lapisan tersembunyi

c. Pada penentuan banyaknya lapisan tersembunyi menggunakan $K$-Means cluster dan dengan menggunakan trial dan error pada 2 sampai 3 cluster (Prasetyo 2012). 


$$
d_{(x, c)}=\sqrt{\sum_{j=1}^{n}\left(X_{i j}-C_{i j}\right)}
$$

d. Menghitung nilai fungsi aktivasi dengan menggunakan fungsi Gaussian Persamaan sebagai berikut (Paliwal and Kumar 2009).

$$
\begin{gathered}
\phi_{j}(x)=e^{\left(-\frac{\mathbf{x}^{2}}{2 \sigma_{j}^{2}}\right)} \\
x=\left\|\mathbf{x}-\mu_{j}\right\|
\end{gathered}
$$

dengan :

$\sigma$ : jarak maksimum pada masing masing cluster

$x$ : Norm Euclidean antara vektor input $\mathrm{x}$ dengan pusat lapisan tersembunyi

$\mu$ : nilai pusat pada lapisan tersembunyi

$\mathbf{x}:\left[\mathrm{x}_{1}, \mathrm{x}_{2}, \ldots, \mathrm{x}_{\mathrm{t}}\right]$ yang merupakan vektor input.

e. Menghitung nilai bobot dan bobot bias dengan menggunakan metode least square pada Persamaan sebagai berikut (Howlett and Jain 2001).

$$
\hat{\mathbf{w}}=\left(\boldsymbol{\Phi}^{\mathbf{T}} \boldsymbol{\Phi}\right)^{-1} \boldsymbol{\Phi}^{\mathbf{T}} \mathbf{X}_{t}
$$

f. Menghitung nilai fungsi output dengan menggunakan rumus sebagai berikut (Paliwal and Kumar 2009).

$$
\hat{X}_{t}=\sum_{j=1}^{m} w_{j} \phi_{j}(\mathbf{x})+w_{b}
$$

dengan :

$m \quad$ : banyak neuron lapisan tersembunyi

$w_{j} \quad$ : bobot dari neuron lapisan tersembunyi ke output, ke-j=1,2...,m

$w_{b} \quad$ : bobot bias

$\phi_{j}(x)$ : fungsi aktivasi neuron tersembunyi ke-j

4. Menghitung akurasi peramalan

Pada proses ini dilakukan perhitungan untuk akurasi peramalan dengan menggunakan data testing agar dapat diketahui berupa besar kesalahan dengan melihat nilai MAPE terkecil untuk meramalkan seluruh data menggunakan rumus sebagai berikut (Makridakis et al. 1999).

$$
\mathrm{MAPE}=\frac{1}{n} \sum_{t=1}^{n} \frac{\left|X_{t}-\hat{X}_{t}\right|}{X_{t}} \times 100 \%
$$

dengan:

$X_{t} \quad$ : observasi pada periode ke- $t$

$\hat{X}_{t} \quad$ : ramalan pada periode ke- $t$

$n$ : banyaknya data 


\section{Meramalkan data}

Menggunakan data aktual testing dengan proporsi yang memiliki akurasi paling minimum untuk peramalan data periode selanjutnya menggunakan rumus Persamaan (4).

\section{HASIL DAN PEMBAHASAN}

\subsection{Data Penelitian}

Data yang digunakan merupakan data sekunder dari website resmi NASA yaitu National Aeronautics and Space Administration (NASA). Data penelitian adalah data jumlah titik panas di Provinsi Kalimantan Timur bulan Januari 2010 sampai dengan Desember 2019. Data tersebut ditampilkan pada time series plot Gambar 1.

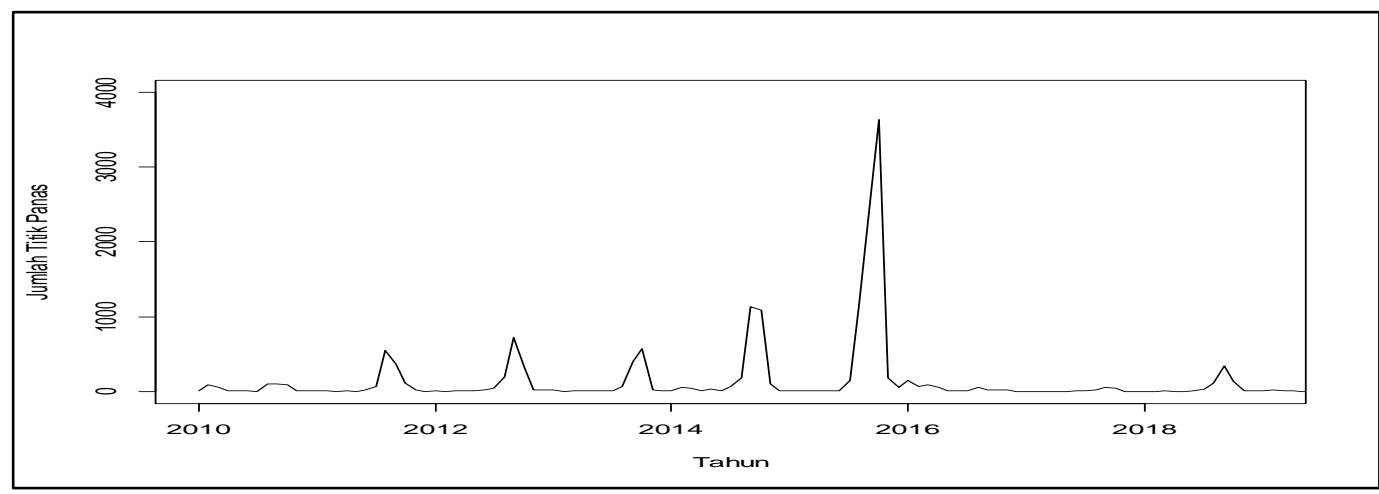

Gambar 1. Grafik runtun waktu jumlah titik panas Provinsi Kalimantan Timur

Berdasarkan Gambar 1 menunjukkan bahwa jumlah titik panas Provinsi Kalimantan Timur mengalami fluktuasi. Jumlah titik panas di Kalimantan Timur terendah sebanyak 1 titik panas dan paling tinggi yaitu 3.630 titik panas pada bulan Oktober 2015.

\subsection{Membagi Data Training dan Data Testing}

Pada penelitian ini proporsi data training dan data testing yang digunakan adalah 70:30, 80:20, dan 90:10. Banyak data training dan data testing menggunakan perbandingan yang merupakan persentase dari jumlah seluruh data. Salah satu pembagian proporsi data 80:20 dimulai 80\% dari 120 data yaitu 96 data dimulai dari Januari 2010 sampai Desember 2017 dan data testing yang digunakan 20\% dari 120 data adalah 24 data dari bulan Januari 2018 sampai Desember 2019.

\subsection{Menentukan model RBFNN}

1. Menentukan input jaringan

Pada tahap menentukan input jaringan digunakan identifikasi lag PACF dengan menggunakan data training proporsi $80 \%$ dari data aktual ditampilkan pada Gambar 2 .

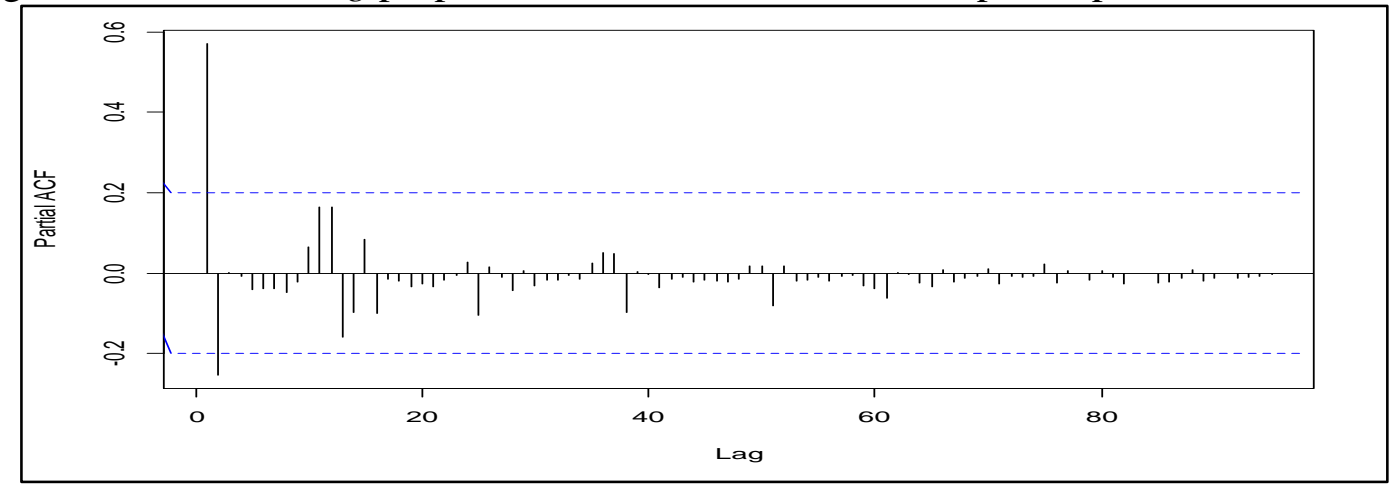

Gambar 2. Identifikasi lag PACF data input jaringan 
Berdasarkan identifikasi lag PACF pada Gambar 2 bahwa lag yang signifikan pada lag 1 dan lag 2, maka diperoleh input $X_{t-1}$ dan $X_{t-2}$ untuk proporsi data 80:20 yang ditampilkan pada Tabel 1 .

Tabel 1. Data input jaringan

\begin{tabular}{cccccccc}
\hline No & $X_{t-2}$ & $X_{t-1}$ & $X_{t}$ & No & $X_{t-2}$ & $X_{t-1}$ & $X_{t}$ \\
\hline 1. & 11 & 85 & 58 & 48. & 6 & 4 & 52 \\
2. & 85 & 58 & 2 & 49. & 4 & 52 & 40 \\
3. & 58 & 2 & 8 & 50. & 52 & 40 & 8 \\
$\vdots$ & $\vdots$ & $\vdots$ & $\vdots$ & $\vdots$ & $\vdots$ & $\vdots$ & $\vdots$ \\
47. & 14 & 6 & 4 & 94. & 44 & 1 & 1 \\
\hline
\end{tabular}

Berdasarkan Tabel 1. Diperoleh data input jaringan dengan proporsi data training dan data testing yang ditentukan. Data input jaringan akan digunakan untuk menentukan model terbaik RBFNN.

2. Menentukan banyaknya lapisan tersembunyi

Pada tahap menentukan banyaknya neuron pada lapisan tersembunyi digunakan metode $K$-Means cluster menggunakan Persamaan (1) agar dapat diketahui nilai setiap pusat dan jarak maksimum. Model RBFNN pada peramalan banyaknya neuron pada lapisan tersembunyi akan menentukan akurasi pada hasil peramalan yang baik digunakan metode trial dan error untuk penentuan nilai $k$ sebagai banyak lapisan tersembunyi dengan menggunakan 2 sampai 3 cluster. Setiap cluster memiliki nilai pusat cluster yang ditentukan secara acak untuk data input $X_{t-1}$ dan $X_{t-2}$, kemudian diperoleh rata-rata jarak dari setiap cluster $(\mu)$ atau pusat cluster. Pada setiap cluster diperoleh jarak maksimum $(\sigma)$ antara pusat cluster dengan data input $X_{t-1}$ yang diperoleh pada Tabel 2.

Tabel 2. Nilai Pusat dan Jarak Maksimum 2 dan 3 Cluster

\begin{tabular}{crcccr}
\hline & \multicolumn{2}{c}{ 2 Cluster } & \multicolumn{3}{c}{3 Cluster } \\
\cline { 2 - 6 } & Cluster 1 & Cluster 2 & Cluster 1 & Cluster 2 & Cluster 3 \\
\hline$X_{t-1}$ & 85,6111 & $1.848,5000$ & 665,1111 & $2.103,6667$ & 34,1707 \\
\hline$X_{t-2}$ & 74,3111 & $2.105,2500$ & 495,7778 & $2.429,6667$ & 40,9512 \\
\hline Jarak Maksimum $(\sigma)$ & $1.069,9290$ & $2.263,9490$ & 812,8953 & $2.271,6860$ & 531,4310 \\
\hline
\end{tabular}

Berdasarkan Tabel 2 setiap cluster memiliki nilai pusat dan jarak maksimum yang menunjukkan terdapat jarak tiap data $\mathrm{X}_{\mathrm{t}-1}, \mathrm{X}_{\mathrm{t}-2}$ dengan nilai pusat. Sehingga diperoleh pada 2 cluster jarak maksimum antara nilai pusat dan data $\mathrm{X}_{\mathrm{t}-1}, \mathrm{X}_{\mathrm{t}-2}$ sebesar 1.069,9290 dan 2.263,9490. Pada 3 cluster diperoleh besar jarak antara data Xt-1 dan Xt-2 menuju nilai pusat yaitu 812,$8953 ; 2.271,6860 ; 531,4310$. Pada setiap jarak cluster memiliki jarak maksimum antara data $\mathrm{X}_{\mathrm{t}-1}, \mathrm{X}_{\mathrm{t}-2}$ dengan nilai pusat data yang dilambangkan dengan sigma.

3. Menghitung nilai fungsi aktivasi

Perhitungan nilai fungsi aktivasi akan digunakan untuk menentukan nilai bobot dengan menggunakan Persamaan (2). Perhitungan yang sama sampai dengan 3 cluster untuk setiap proporsi. Setelah dilakukan perhitungan nilai fungsi aktivasi didapatkan matriks desain Gaussian $\left(\Phi_{0}\right)$ dengan ordo $94 \times 2$ sebagai berikut : 


$$
\Phi_{0}=\left[\begin{array}{cc}
0,9983 & 0,4813 \\
0,9996 & 0,4912 \\
0,9968 & 0,4764 \\
\vdots & \vdots \\
0,9965 & 0,4736
\end{array}\right]_{94 \times 2}
$$

4. Menghitung nilai bobot dan bobot bias

Pada perhitungan nilai bobot menggunakan matriks Gaussian yang didapat pada perhitungan fungsi aktivasi dan ditambahkan 1 kolom untuk bobot bias yang bernilai (1) menjadi :

$$
\Phi=\left[\begin{array}{ccc}
0,9957 & 0,4684 & 1 \\
0,9951 & 0,4673 & 1 \\
0,9995 & 0,4994 & 1 \\
\vdots & \vdots & \vdots \\
\underbrace{0,9965}_{\phi_{1}} & \underbrace{0,4736}_{\phi_{2}} & 1 \\
\phi_{\text {bias }}
\end{array}\right]_{94 \times 3}
$$

Kemudian nilai bobot optimum ( $\hat{\mathbf{w}})$ yang terdiri dari nilai bobot $w_{1}, w_{2}$ dan bobot bias $\left(w_{b}\right)$ untuk 2 cluster menggunakan Persamaan (3) dan diperoleh hasil nilai bobot sebagai berikut:

$$
\begin{aligned}
& \hat{\mathbf{W}}=\left(\boldsymbol{\Phi}^{\mathbf{T}} \boldsymbol{\Phi}\right)^{-1} \boldsymbol{\Phi}^{\mathbf{T}} \mathbf{X}_{t} \\
& =\left(\left[\begin{array}{cccc}
0,9983 & 0,9996 & \cdots & 0,9965 \\
0,4813 & 0,4912 & \cdots & 0,4763 \\
1 & 1 & \cdots & 1
\end{array}\right]\left[\begin{array}{ccc}
0,9983 & 0,4813 & 1 \\
0,9996 & 0,4912 & 1 \\
\vdots & \vdots & \vdots \\
0,9965 & 0,4763 & 1
\end{array}\right]\right)^{-1} \times \\
& {\left[\begin{array}{cccc}
0,9983 & 0,9996 & \cdots & 0,9965 \\
0,4813 & 0,4912 & \cdots & 0,4763 \\
1 & 1 & \cdots & 1
\end{array}\right]\left[\begin{array}{c}
58 \\
2 \\
\vdots \\
1
\end{array}\right]} \\
& \hat{\mathbf{w}}=\left(\begin{array}{l}
w_{1} \\
w_{2} \\
w_{b}
\end{array}\right)=\left[\begin{array}{c}
-235,3120 \\
3.063,7731 \\
-1.165,1342
\end{array}\right]
\end{aligned}
$$

Untuk bobot bias 3 cluster diperoleh sebagai berikut:

$$
\hat{\mathbf{w}}=\left[\begin{array}{c}
w_{1} \\
w_{2} \\
w_{3} \\
w_{b}
\end{array}\right]=\left[\begin{array}{c}
-22,0234 \\
3.264,5149 \\
106,96882 \\
-1.256,2464
\end{array}\right]
$$

5. Menghitung nilai output data testing 
Pada tahap menghitung nilai output akan diperoleh nilai hasil peramalan data testing untuk setiap proporsi menggunakan Persamaan (4). Periode peramalan merupakan banyaknya data testing. Berikut hasil output untuk setiap proporsi.

Tabel 3. Nilai output proporsi 70:30

\begin{tabular}{ccrrrrrrr}
\hline No. & 2 cluster & 3 cluster & No. & 2 cluster & 3 cluster & No. & 2 cluster & 3 cluster \\
\hline 85. & 42,6926 & 56 & 97. & 32 & 46 & 109. & 38 & 52 \\
86. & 32,015 & 46 & 98. & 32 & 46 & 110. & 38 & 52 \\
87. & 32,015 & 46 & 99. & 32 & 46 & 111. & 40 & 54 \\
$\vdots$ & $\vdots$ & $\vdots$ & $\vdots$ & $\vdots$ & $\vdots$ & $\vdots$ & $\vdots$ & $\vdots$ \\
96. & 56,2693 & 70 & 108. & 109 & 118 & 120. & 186 & 187 \\
\hline
\end{tabular}

Tabel 4. Nilai output Proporsi 80:20

\begin{tabular}{rrrrrr}
\hline No. & 2 cluster & 3 cluster & No. & 2 cluster & 3 cluster \\
\hline 97. & 27 & 38 & 109 & 33 & 45 \\
98. & 27 & 38 & 110. & 32 & 44 \\
99. & 27 & 38 & 111. & 36 & 47 \\
$\vdots$ & $\vdots$ & $\vdots$ & $\vdots$ & $\vdots$ & $\vdots$ \\
108. & 95 & 101 & 120. & 169 & 166 \\
\hline
\end{tabular}

Tabel 5. Nilai output Proporsi 90:10

\begin{tabular}{crr}
\hline No & 2 Cluster & 3 Cluster \\
\hline 109. & 31 & 43 \\
110. & 31 & 43 \\
111. & 33 & 44 \\
$\vdots$ & $\vdots$ & $\vdots$ \\
120. & 176 & 172 \\
\hline
\end{tabular}

Pada Tabel 3. Merupakan nilai output atau hasil peramalan dengan proporsi data testing 30\% dari semua data diperoleh 36 data output. Proporsi data testing $20 \%$ diperoleh data nilai output 24 data pada Tabel 5. Nilai output data testing proporsi $10 \%$ di Tabel 5 diperoleh 12 data peramalan.

\subsection{Akurasi peramalan}

Perhitungan akurasi peramalan digunakan untuk menentukan banyaknya lapisan tersembunyi dalam model RBFNN dimana cluster yang digunakan dalam model peramalan data periode berikutnya. 
Tabel 6. Hasil Perhitungan MAPE

\begin{tabular}{cccc}
\hline \multirow{2}{*}{ Banyak Cluster } & \multicolumn{3}{c}{ Proporsi Data Testing dan Data Traning } \\
& $70: 30$ & $80: 20$ & $90: 10$ \\
\hline 2 & $2.425,7690$ & $2.019,2520$ & $2.343,0510$ \\
3 & $2.996,0270$ & $2.347,0350$ & $2.555,1890$ \\
\hline
\end{tabular}

Berdasarkan Tabel 6. menunjukkan bahwa proporsi data training dan data testing 70:30,80:20, dan 90:10 dengan lapisan tersembunyi trial dan error 2 sampai 3 cluster yang memiliki nilai MAPE terkecil yaitu proporsi 80:20 dengan 2 lapisan tersembunyi sebesar $2.019,2520 \%$. Oleh karena itu, dapat diambil kesimpulan bahwa yang digunakan untuk meramalkan data periode berikutnya proporsi 80:20 dengan 2 lapisan tersembunyi.

\subsection{Meramalkan data}

Pada tahap meramalkan data untuk periode selanjutnya menggunakan data aktual testing dengan proporsi $20 \%$ dari seluruh data yaitu 24 data dari bulan Januari 2018 sampai Desember 2019.

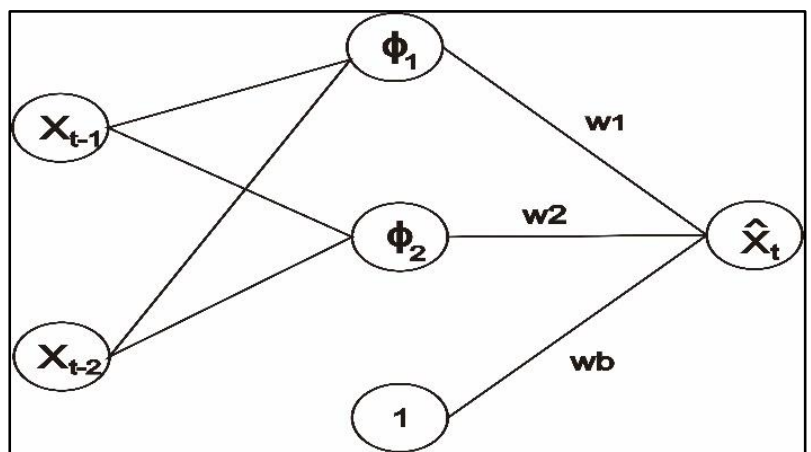

Gambar 3. Arsitektur jaringan RBFNN jumlah titik panas Provinsi Kalimantan Timur Menggunakan 2 Kluster

Selanjutnya, nilai ouput yang diperoleh merupakan nilai hasil peramalan menggunakan Persamaan (4). Banyak periode peramalan yang akan dilakukan yaitu tiga bulan periode ke depan pada tahun 2020 dan diperoleh hasil peramalan bulan Januari terdapat 55 titik panas, Februari 54 titik panas dan Maret ada 84 titik panas. Hasil data testing dan peramalan untuk ditampilkan pada Gambar 4 sebagai berikut:

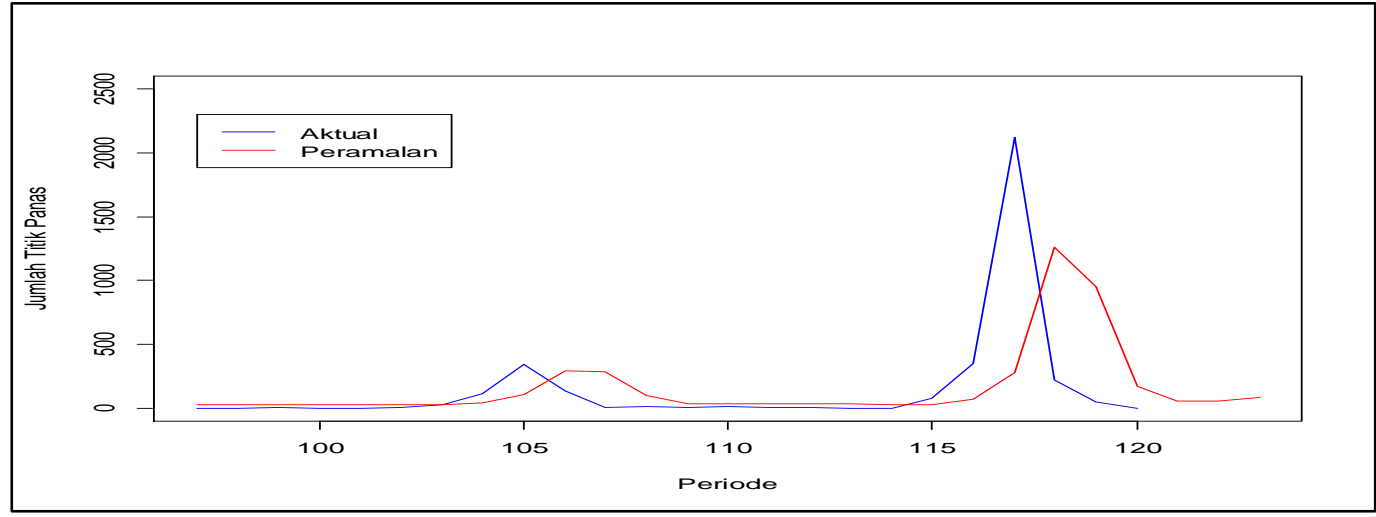

Gambar 4. Grafik data aktual testing dan hasil peramalan 
Pada Gambar 4. memperlihatkan data aktual testing dan hasil peramalan jumlah titik panas di Provinsi Kalimantan Timur dari bulan Januari 2018 sampai dengan bulan Maret 2020 mengalami fluktuasi. Jumlah titik panas terbesar pada bulan September 2019 sebesar 2.124 titik panas di Provinsi Kalimantan Timur. Data hasil peramalan tidak mengikuti pola data aktual testing dikarenakan jika data sangat fluktuaktif, hasil peramalan dengan menggunakan RBFNN akan memberikan bias cenderung besar karena memiliki nilai MAPE yang tinggi.

\section{Kesimpulan}

Proses pembentukan model RBFNN pada data runtun waktu jumlah titik panas di Provinsi Kalimantan Timur memiliki model terbaik dengan 2 input jaringan yaitu $X_{t-1}$ dan $X_{t-2}$. Berdasarkan proses tersebut jumlah titik panas di Provinsi Kalimantan Timur menggunakan metode RBFNN yang memiliki tingkat akurasi paling baik adalah menggunakan 2 input jaringan dan 2 lapisan tersembunyi. Hasil peramalan jumlah titik panas menggunakan metode RBFNN yang diperoleh selama 3 periode dari bulan Januari 2020 sampai Maret 2020 menunjukkan terjadi penurunan pada bulan Januari 2020 sampai Februari 2020 dan kenaikan di bulan Maret 2020.

\section{DAFTAR PUSTAKA}

Aswi, A., and Sukarna, S. (2006), Analisis Deret Waktu Analisis Deret Waktu, Makassar: Andira Publisher.

Direktorat Pengendalian Kebakaran Hutan dan Lahan (2021), "SiPongi - Karhutla Monitoring Sistem," Available athttp://sipongi.menlhk.go.id/hotspot/luas_kebakaran.

Howlett, R. J., and Jain, L. C. (2001), Radial basis function networks 2: New Advances in Design, Mathematics Today, Berlin: Springer-Verlag.

Laksmi, P. I. O., Dharmawan, K., and Ida Harini, L. P. (2014), "Peramalan Kunjungan Wisatawan Menggunakan Model Armax Dengan Nilai Kurs Dan Ekspor-Impor Sebagai Faktor Eksogen,” E-Jurnal Matematika, 3, 138. https://doi.org/10.24843/MTK.2014.v03.i04.p076.

Makridakis, S., Wheelwright C, S., and McGee, V. E. (1999), Metode dan Aplikasi Peramalan, Binarupa Aksara.

Nievergelt, J. (1969), "R69-13 Perceptrons: An Introduction to Computational Geometry," IEEE Transactions on Computers, C-18, 572-572. https://doi.org/10.1109/TC.1969.222718.

Nikentari, N., Bettiza, M., and Sastypratiwi, H. (2018), "Prediksi Kecepatan Angin Menggunakan Adaptive Neuro Fuzzy (ANFIS) dan Radial Basis Function Neural Network (RBFNN)," Jurnal Edukasi dan Penelitian Informatika (JEPIN), 4, 70. https://doi.org/10.26418/jp.v4i1.25558.

Palit, A. K., and Popović, D. (2005), Computational intelligence in time series forecasting : theory and engineering applications, London: Springer-Verlag.

Paliwal, M., and Kumar, U. A. (2009), "Neural networks and statistical techniques: A review of applications," Expert Systems with Applications, 36, 2-17. https://doi.org/10.1016/j.eswa.2007.10.005.

Prasetyo, E. (2012), Data Mining: konsep dan aplikasi menggunakan MATLAB, Yogyakarta: Andi.

Shoolihah, A.-M., Furqon, M. T., and Widodo, A. W. (2017), "Implementasi Metode Improved K-Means untuk Mengelompokkan Titik Panas Bumi," Jurnal Pengembangan Teknologi Informasi dan Ilmu Komputer (J-PTIIK) Universitas Brawijaya, 1, 1270-1276. 
Tim Publikasi Kata Data (2019), "Luas Gambut Indonesia Terbesar Kedua di Dunia Infografik Katadata.co.id," Available athttps://katadata.co.id/timpublikasikatadata/infografik/5e9a519433cb1/luas-gambutindonesia-terbesar-kedua-di-dunia.

Warsito, B. (2009), Kapita Selekta Statistika Neural Network, Semarang: Badan Penerbit UNDIP Semarang. 